Alain Sicard
Catedrático de literatura latinoamericana
en la Universidad de Poitiers y director del
Centro de investigaciones latinoamerica-
nas de la misma universidad, es autor de
varios libros entre los que destaca El pen-
samiento poético de Pablo Neruda (1981),
poeta del que ha sido traductor. Es director
de los Coloquios Internacionales de Poi-
tiers en los que se ha estudiado sistemáti-
camente una parte importante de los
autores contemporáneos latinoamericanos.
Es autor de numerosos artículos sobre
autores contemporáneos.

1

Navegaciones y regresos es el título de un libro de poemas publicado por el poeta en 1959 (Pablo Neruda, Obras Completas, Buenos Aires, Losada, tercera edición, 1968, pp. 181-283 (Todas las citaciones se harán en esta edición).

2

Pablo Neruda: "El episodio", Memorial de isla Negra v: «Sonata crítica» oc Il. p. 643.

Pablo Neruda: Divagaciones y regresos

ALAIN SICARD

\title{
PABLO NERUDA: DIVAGACIONES Y REGRESOS
}

\author{
ALAIN SICARD
}

«...por eso atesoro las equivocaciones de mi canto"

P.N.

El título que se me ha ocurrido dar a estas reflexiones, si no es muy explícito en cuanto a su contenido, dice bien de lo que no se tratará: ni del examen de un aspecto inédito de la obra del poeta, ni de un estudio sistemático y riguroso — no me atrevo a decir científico: la palabra divagación connota todo lo contrario. Estas divagaciones mías tienen un rumbo bastante incierto, a diferencia de las navegaciones nerudianas torpemente parodiadas ${ }^{1}$ por el título. Éste, en realidad, debería leerse al revés: «Regresos y divagaciones»: regresos sobre determinados temas y problemas nerudianos, con la esperanza de que susciten en quien los viene navegando desde hace casi cuarenta años algunas divagaciones críticas y auto-críticas. Más que un balance otoñal, más que un memorial melancólico de mis viajes por el océano nerudiano, este texto quisiera sacar en claro, fuera de toda auto-contemplación o auto-complacencia, mi apasionada, admirativa, al mismo tiempo que difícil y contradictoria relación con la poesía del gran chileno: mis entusiasmos y mis insatisfacciones, mis dudas y mi fe en el porvenir de esta poesía.

Antes de cerrar este preámbulo, quiero expresar mi agradecimiento a todos los que estuvieron embarcados conmigo durante todos esos años en la misma nave, ayudándome con su aprobaciones o desacuerdos. Quiero decir la deuda que tengo, de un modo muy especial, con tres de esos marineros de la crítica nerudiana: Hernán Loyola, Jaime Concha y Roberto Pring-Mill.

Mis dudas: la primera de ellas concierne probablemente a la posibilidad de reflexionar con la objetividad que, según dicen, requiere la investigación científica, sobre este objeto tan particular que es la literatura, y más si se trata de poesía - más aún si se trata de la poesía de alguien que fue compañero y amigo. Interrogarme sobre esta obra, más que sobre ninguna, fue interrogarme también sobre mí mismo. «Quién soy?» preguntaba el memorialista de Isla Negra. "Muchos somos», contestaba. Como el poeta, el crítico tiene varias vidas, por más oscuras que sean y desprovistas de interés que estén. Los sucesivos análisis que él hace están sometidos a las vicisitudes de la historia - y de su propia historia dentro de la historia - de modo que la obra termina funcionando como un espejo cóncavo que le devuelve las distorsiones que el curso de los años impuso a su propia existencia.

Cuando decidí, poco antes de finalizar los años cincuenta, trabajar en una obra que iba a ocuparme de manera exclusiva durante diez años, y que hasta hoy me sigue acompañando, estábamos muy lejos de imaginar algo parecido a la caída del muro de Berlín. La llegada al poder de De Gaulle, así como dos años de guerra colonialista en Argelia me habían conducido a hacerme miembro del Partido Comunista Francés. La imagen de Neruda que todavía imperaba entonces era la del poeta militante. Stalin descansaba bajo la tierra, pero sus cenizas estaban tibias todavía. La revelación hecha por Kruschov de los crímenes del «bigotudo dios con botas puestas» ${ }^{2}$ había causado en la parte más lúcida de los militantes dramas de conciencia terribles. En el año sesenta Neruda publicó Estravagario donde, con mucha dignidad, iniciaba una 
reflexión auto-crítica que iba a proseguir en los libros posteriores, pero sin renegar jamás de su fe comunista. «No me esperen de regreso», escribía con soberbia, «No soy de los que vuelven de la luz»33: una luz que todavía iluminaba muchos importantes sectores del horizonte histórico, una luz que se llamaba Viet-Nam, o Cuba, antes de llamarse Chile. Los comunistas podíamos repetir las orgullosas palabras del poeta cuyo lirismo tal vez disculpa el carácter excesivo:

Somos la plata pura de la tierra, el verdadero mineral del hombre, encarnamos el mar que continúa: la fortificación de la esperanza: un minuto de sombra no nos ciega: con ninguna agonía moriremos. ${ }^{4}$

"Un minuto de sombra no nos ciega...»: Este verso da la medida - enseña el límitede nuestra aprehensión del fenómeno en aquellos años. En otras partes del mismo poema, Neruda habla de «la luna sombría del eclipse». «La historia», dice, «se apagó un minuto...». Veíamos ingenuamente el stalinismo como una excrecencia aberrante pero pasajera, cuyo carácter canceroso no sospechábamos, o no queríamos reconocer, un tumor que la historia había generado, pero que ella, en su infinita sabiduría - y el dios de la Dialéctica mediante- ya había extirpado

...porque ya murió la verdad

Y ahora podemos ser justos. ${ }^{5}$

La verdad del dogma había muerto, y otra verdad renacía, contradictoria, difícil. Nos embriagábamos de lucidez dolorosa como antes de ilusiones heroicas Para completar esta evocación cuyo carácter autobiográfico espero me sea perdonado, añadiré que, aunque mi marxismo era de estirpe sartriana y más bien ético, yo compartía — sigo compartiendo en sus aspectos esenciales- la visión que el materialismo histórico propone de la sociedad y de su organización económica. Pero, aplicados al arte y a la literatura, los análisis marxistas me dejaban insatisfecho. Si debo confesar la verdad, tenía la impresión de que poco me servían para el trabajo que emprendía. Además el panorama intelectual se iba poblando de tentaciones: el freudismo, que pronto se iba a volver lacaniano, estaba conquistando su definitivo derecho de ciudadanía en los estudios literarios, y, sobre todo, la ola estructuralista alcanzaba las orillas de una crítica francesa siempre sedienta de novedades. Empezaba la religión del texto que tantos avances y tantos estragos había de causar entre nosotros - y luego entre nuestros desafortunados estudiantes. El libro que yo estaba preparando (no recuerdo si aún se llamaba El pensamiento poético de Pablo $N_{\text {eruda }}$ ) se volvió un campo de batalla entre una lectura sincrónica de la obra, influida por la rama temática de la crítica «estructuralista», y una lectura diacrónica que me parecía inevitable ante un poeta tan movedizo y tan estrechamente ligado al movimiento de la historia como lo era Neruda. Creo que la segunda lectura acabó por dominar sobre la primera, pero para poder calmar mis escrúpulos marxistas, adopté una solución intermediaria: perspectiva diacrónica hasta 1936, y sincronía después, haciendo coincidir, al salir de la Segunda Residencia, la aparición de la noción de materia con la toma de conciencia política, solución hasta cierto punto discutible, ya que, como veremos, la noción de materia forjada en Residencia en la tierra - y que resurgiría después de 1960 - no era la misma que aquélla que iba prevalecer en el Canto General y en las sucesivas Odas elementales.

Había decidido centrar mi trabajo sobre la noción de materia, por la evidente importancia del tema en el universo de Neruda, pero también, para evitar un estudio de carácter histórico-biográfico que me hubiera encerrado - por lo menos eso temía - en la irritante, aunque insoslayable, problemática del «compromiso». En los años sesenta era todavía muy fuerte la idea, nacida con la adhesión del poeta al Partido comunista chileno y la publicación del Canto General, de que existían dos nerudas incompatibles, y quienes aborrecían al Neruda luminoso del Canto o de la Odas, ensalzaban melancólicamente al sombrío poeta de las Residencias. Y viceversa. Mi propósito $-\mathrm{y}$, creo, el de la parte más lúcida de la crítica nerudiana- era poner fin a esta dicotomía - a la que, dicho sea de paso, el propio Neruda contribuyera con sus declaraciones-, y sacar a relucir la unidad profunda del universo del poeta. Así fue como descubrí una génesis interna de la noción de materia en las dos primeras Resi-
5

Pablo Neruda: «Tal vez tenemos tiempo", Memorial de Isla Negra V, "Sonata crítica", op. cit. p. 639.

6

Alain Sicard: El pensamiento poético de Pablo Neruda, Madrid, Editorial Gredos, 1981.

Pablo Neruda: Divagaciones $y$ regresos

ALAIN SICARD 
Pablo Neruda: "Entrada a la madera", Residencia en la tierra II, IV «Tres cantos materiales», oc, l, op. cit. p. 233.

8

Pablo Neruda: "La noche", Memorial de Isla Negra V: Sonata crítica, oc, II, p. 634 .

9

Pablo Neruda: "La línea de madera", Canto general XV: Yo soy, op. cit. p. 709).

10

Pablo Neruda: La espada encendida, Buenos Aires, Losada, 1970.

11

Es el tífulo del largo poema dedicado al stalinismo en el quinto volumen del Memorial, Sonata crítica. dencias donde la angustia metafísica generaba una extraña objetivación del fenómeno temporal.

Este hallazgo - tardé un poco en darme cuenta de ello- rompía del esquema que había elegido para mi libro según el modelo muy nerudiano —nerudiano de los tiempos del Canto General- de una "prehistoria idealista» del poeta superada por el nacimiento a un "nuevo ser», el ser histórico, materialista - materialista/histórico- brotado de la conciencia política.

El problema que entonces me disimulé era que la definición ideologizada de la materia - definición exterior a la experiencia propiamente poética y que iba a dominar durante casi veinte años buena parte de la poesía de Neruda - era profundamente ajena y finalmente antitética con respecto a aquélla que se habla venido elaborando en lo más hondo de la experiencia del sujeto durante su atroz «saison en enfer» residenciaria. Pero ese hallazgo que hice, en las Residencias, de un tiempo objetivado en materia representó un paso decisivo en la medida en que de allí iba a salir, fruto a-histórico de la metafísica temporal, el concepto central de mi tesis, lo que llamé «lo deshabitado». Recordaré brevemente su definición.

Entiendo por Lo deshabitado una versión a-histórica de la materia, una materia sin el hombre: algo como una versión laica de la eternidad. "Entrada a la madera", en la Segunda Residencia, constituye una magistral ilustración de ese «deshabitarse» del sujeto poético para realizar su fusión utópica con una madera/materia hecha de tiempo acumulado en lo más hondo del recuerdo de la infancia. El mismo recuerdo recurrente reproducirá a lo largo de la producción nerudiana ese gesto poético fundamental de «entrada en las cosas por un acto de arrebatado amor», como, unos treinta años después, en el poema de Memorial de Isla Negra titulado "La noche" en el que el sujeto poético se auto-describe

Inmóvil con secreta vida corno una ciudad subterránea que se fatigó de sus calles, que se escondió bajo la tierra y nadie sabe que existe, no tiene manos ni almacenes, se alimenta de su silencio.
Alguna vez ser invisible,

hablar sin palabras, oír

sólo cierta gotas de lluvia,

sólo el vuelo de cierta sombra ${ }^{8}$

En resumen: partiendo de la idea de restaurar la unidad de proyecto nerudiano, me encontraba con una versión de la materia y con una poética en radical oposición con respecto a su versión histórico/épica y a la poética del trabajo que el compromiso político instauró en la obra entre 1940 y 1960, para usar cifras redondas.

No es mi propósito aquí resumir mi libro. Baste decir que en él trato de mostrar cómo, a partir de la crisis ideológica abierta por las revelaciones de Kruschov, la poética nocturna del sumergido, del carpintero ciego ${ }^{9}$ llega a ocupar en la obra el puesto esencial, pero sin sustituir la poética militante, más bien articulándose con ella dentro de una dialéctica ejemplarizada por La espada encendida ${ }^{10}$. Deshabitarse aparecía entonces como un nuevo «deber» del sujeto agobiado por un siglo terriblemente «permanente» y envuelto en sangre y ceniza: un paradójico deber de ruptura con la historia necesario para que ella realice su renovación.

Sigo creyendo en esa tentativa de dialectalización que representa la última tentativa del poeta, en La espada encendida, para restaurar la esperanza, y no cambiaría nada a los análisis que yo hice al respecto. Sólo les quitaría, tal vez, un poco de su serenidad: todos sabemos que Neruda murió desesperado. Sin embargo, me parece hoy que la agónica voluntad de esperar que yo compartía con el poeta me impidió profundizar todo lo que no entrara en esa dialectalización, y medir el lastre que representaba dentro de la obra $-y$ fuera de ella - la herencia de la guerra fría: la ideología del dogma staliniano.

El arte no fue la sola ni la principal víctima del dogmatismo que terminó usurpando, durante aquellos años, esta ideología de la vida y del movimiento que quiere ser el marxismo.

\section{Aquel inmóvil gobernó la vida.}

dice Neruda de Stalin en la Sonata crítica. Es difícil dar un mejor resumen de aquello que fúe mucho más que un simple «episodio»"1, como lo creía el poeta y como lo creíamos. 
El espacio falta aquí -y tampoco es el lugar- para someter la ideología staliniana a un examen general que mostraría cómo el marxismo dogmático, al someter todas las prácticas a un mismo molde, las esterilizaba y acababa con su dinamismo creador. En el campo que aquí interesa, la consecuencia más importante del dogmatismo fue una instrumentalización del lenguaje poético y la negación de su carácter específico. Por eso la mejor manera de abordar el problema de sus eventuales efectos en el proyecto nerudiano sea tal vez recordar en qué consistía la especificidad de este proyecto. Trataremos de examinar cómo la ideología socalista de aquellos años amenaza — sin conseguirlo jamás de modo uniforme- desviarlo en su provecho, pero, sobre todo, comprobaremos cómo el genio del poeta acaba integrando a su propio sistema, trascendiéndolos, elementos que hubieran podido ocasionar su pérdida.

Me limitaré a los tres aspectos que al respecto me parecen esenciales: la autorreferencialidad; la temporalidad; $y$ la ambición totalizadora, epíteto interesante por su relación -y, como veremos, su radical oposición- con el de totalitario.

La autorreferencialidad, a la que Hernán Loyola dedicó magníficas páginas, no comienza con la ideologización del proyecto poético, pero ésta le abre un nuevo espacio.

Desde sus principios, la poesía de Neruda es autobiográfica. Pero la mitificación por el poeta de su propia imagen aparece con el compromiso político y la adhesión ideológica. Neruda $-y$ con él otros poetas de aquel período- no hace sino reanudar con la imagen del poeta-profeta que, a fines del siglo XVIII y durante buena parte del siglo XIX, laiciza y asume poderes que antes correspondian a la Iglesia o a la Tradición. Cuando empieza nuestro siglo, la especificación de la práctica literaria está ya muy avanzada, y solamente quedará interrumpida no tanto por la segunda guerra mundial como, en los años inmediatamente posteriores, por la tentativa de hegemonía del marxismo en su versión soviética.

Neruda, decíamos, reanuda con la tradición mesiánica de Hugo, de Tolstoï o de Whitman, pero dentro de un contexto ideológico que es el de la guerra fría y el stalinismo. El resultado es esa oficialización de la figura del poeta al mismo tiempo que su proyección planetaria favorecida por los múltiples canales de los que el Partido Comunista internacionalmente dispone.

Por otra parte, esta mitificación del poeta crea con sus lectores una relación singular y contradictoria. Neruda se encontraba con el pueblo chileno en una asombrosa simbiosis. No se borrará de mi memoria aquel viejo obrero del salitre que, después de contarme la historia de su vida, me dijo su nombre con una frase que resultó ser el primer verso de un poema de La tierra se llama Juan

\section{Camarada, me llamo Luis Cortés...'2}

El azar -o el dios de los nerudistas?había querido que un héroe del Canto a quien hasta esa fecha yo había considerado como un ente de pura ficción, cruzara mi camino por la pampa chilena en aquel año 1971. Ni tampoco olvidaré el orgullo que brillaba en los ojos de aquel niño haraposo al preguntarme, en aquella noche lluviosa en Puerto-Montt, si conocía a un poeta que estaba de embajador en mi país. Semejante reconocimiento de un poeta por su pueblo impresiona y conmueve, pero no se puede menoscabar la parte ocupa$\mathrm{da}$, en ese fervor que podía llegar a excesos casi religiosos, de toda una mitología heroica del poeta nacional que rebasa el ámbito de la sola poesía.

La temporalidad es otro elemento fundador de la especificidad del proyecto nerudiano en la medida en que su expresión es una constante de la obra desde el comienzo hasta los poemas póstumos. Por eso es sintomático el eclipse que esta preocupación sufre durante un período determinado que coincide con el de mayor ideologización de la poesía del chileno.

El sujeto histórico, en el Canto General y, luego, en las Odas, evacua de un modo que se quiere definitivo el sujeto temporal con su séquito de angustias y de lamentos. Es el nacimiento de un nuevo ser, milagrosamente abstraido del flujo de muertes que constituyen nuestras vidas, que Alturas de Macchu Picchu celebran magníficamente. Ahora bien: ese nuevo ser, por más sincero y exaltante que sea, echa sus raíces dentro del concepto de la historia difundido por el marxismo dogmático de la época y del cual evocaré solamente dos aspectos.
12

Pablo Neruda: Canto General VIII: La fierra se llama Juan III: "Luis Cortés (de Tocopilla)", op. cit. p. 555. 
Pablo Neruda: "El hombre invisible", Odas elementales, op. cit. I p. 1003.

14

Pablo Neruda: Confieso que he vivido-Memorias (Buenos Aires, losada, 1974).

15

Pablo Neruda: "Los soberanos", Las manos del día XXIII, Buenos Aires, Losada, 1968.

16

Pablo Neruda: "La vida": Canto general XV, Yo soy XXII, op. cit. p. 717.

17

Pablo Neruda: "Yo me llamaba Reyes...", El mar y las campanas, Buenos Aires, Losada, p. 23.

Pablo Neruda: Divagaciones $y$ regresos

ALAIN SICARD

Uno es la exaltación del trabajo como actividad fundadora de la humanidad, punto de vista de por sí, no sólo poco criticable sino difícilmente negable, pero que se convierte en dogma a partir del momento en que se quiere extender su definición socio-económica al sector de la creación literaria. La asimilación del trabajo literario al trabajo productor es un leit-motiv de los escritos teóricos del realismo socialista, y también lo es del metalenguaje nerudiano, bien se exprese en poemas o en simples declaraciones: el posta es un obrero del verso, un trabajador que nada se distingue de los otros trabajadores: es «el hombre invisible» ${ }^{13}$ de las Odas elementales cuyo utópico anhelo es desaparecer como sujeto para confundir su canto con el silencio multitudinario de los hombres. Esta negación de la especificidad del trabajo poético, legitimada éticamente por un sincero deseo de comunión con los hombres, es tenaz en la poética nerudiana: domina las reflexiones estéticas contenidas en Confieso que be vivido ${ }^{14}$-muchas de ellas retomadas, es cierto, de declaraciones muy anteriores al libro de memorias. El único libro que reconoce en el poeta aquel «carpintero ciego, sin manos» (evocado más bien para censurarlo en un poema del Canto General, "La línea de madera"), es un libro de 1968 titulado Las manos del día. En este texto, al confesar su culpabilidad por lo que no hizo, el poeta reconoce al sesgo y con una mala conciencia sintomática, su estatuto de «hijo de la luna» improductivo:

Si, soy culpable

de lo que no hice,

de lo que no sembré, corté, medí,

de no haberme incitado a poblar tierras,

de haberme mantenido en los desiertos

y de mi voz hablando con la arena. ${ }^{15}$

El segundo aspecto de la influencia del dogma ideológico está más directamente relacionado con la temporalidad. Se trata del concepto teleológico de la historia que domina la perspectiva del Canto General: al difícil, contradictorio y a veces caótico caminar del progreso humano se superpone el esquema voluntarista y artificial de una Historia iluminada en cada uno de sus pasos por la certeza de la victoria final. Una falsa dialéctica borra cuidadosamente, en nombre de la necesaria superación, el término negativo de la contradicción. El hablante poético del Canto General puede proclamar:

Yo tengo frente a mí sólo semillas, desarrollos radiantes y dulzura. ${ }^{16}$

Es fácil entender cómo la épica va a volverse la forma privilegiada de esta ideología simplificadora, $y$ en otro trabajo ya me he referido al problema planteado por la conjunción, dentro del contexto stalinista, de esa forma poética propensa a la celebración con el culto de la personalidad vigente entre los partidos comunistas de la época. Sin embargo, es preciso, si no matizar este enfoque, injertarle complejidad. En efecto: a posar de la perspectiva voluntarista y más que discutible que sustenta la visión histórica en el Canto General, el libro sigue conmoviéndonos. Cabría preguntarse, dándole la vuelta a nuestra observación precedente, si no es precisamente la épica la que salva el Canto de un enjuiciamiento negativo merced a la lectura propiamente poética y mítica de la historia que impone. No se olvide, además, que la épica que salva el Canto es una épica americana. La tentativa posterior de hacer, con Las uvas y el viento, el canto general del socialismo, será un fracaso poético. Las uvas y el viento carece, a nuestro juicio, de arraigamiento en las zonas profundas y americanas de la experiencia del poeta. Por otra parte, representa un excelente ejemplo de la desviación y de la confiscación por la ideología de otro rasgo especifico del proyecto nerudiano: la ambición totalizadora que examinaremos para terminar.

De los tres rasgos que hemos destacado, éste es probablemente el más esencial. No conoce, como la preocupación temporal, interrupción, pero sí una particular inflexión bajo la influencia de lo ideológico.

La ambición totalizadora nace con la poesía nerudiana aquel día en que, en una casa de madera azotada por la lluvia austral, un muchacho decide dejar de ser Neftalí Ricardo Reyes Basoalto para "ponerse todos los nombres a la vez ${ }^{17}$ y ser Pablo Neruda, el poeta. Pero la ambición totalizadora esperará hasta 1934 para encontrar su primera y definitiva formulación en el manifiesto madrileño «antijuanramonista» titulado «Sobre una poesía sin pureza»: 
"La poesía impura como un traje, como un cuerpo, con manchas de nutrición y actitudes vergonzosas, con arrugas, observaciones, sueños, vigilia, profecías, declaraciones de amor y de odio, bestias, sacudidas, idilios, creencias políticas, negacionès, dudas, afirmaciones, impuestos. La sagrada ley del madrigal, y los decretos del tacto, olfato, gusto, vista, oído, el deseo de justicia, el deseo sexual, el ruido del océano, sin excluir deliberadamente nada, sin aceptar deliberadamente nada, la entrada en la profundidad de las cosas en un acto de arrebatado amor, y el producto poesía manchado de palomas digitales, con huellas de dientes y hielo, roido tal vez levemente por el sudor y el uso.»18

Se puede ver en esta enumeración hasta qué punto el proyecto totalizador de Neruda es, en el período que precede a su ideologización, por esencia caótico. En vez de anexar y ordenar la generalidad, el poeta se entrega a su diversidad infinita. Esta actitud se mantendrá en todo el quehacer nerudiano. Sin embargo, uno de los elementos de la enumeración se diferenciará, a partir del 36 , de los otros para especializarse, con la secreta intención de dominar el caos, de orientarlo, de jerarquizarlo solapadamente: se trata de las "creencias políticas» -inseparables, en el texto, de sus «negaciones»- las cuales, sin alcanzar un carácter propiamente hegemónico, ya impregnarán directa o indirectamente la tota- lidad del proyecto, a expensas, ciertas veces, de la fecunda confusión de lo impuro.

Recuerdo mi reacción al leer, en mis años de aprendiz-nerudista, el libro de un estudioso argentino del poeta intitulado Para una critica a Pablo Neruda ${ }^{19}$. Qué presunción! Qué indecencia! Qué falta de respeto! Yo estaba escandalizado. Llegado al fin de este trabajo, se me ocurre que es posible que mis divagaciones nerudianas susciten en quienes las lean la misma indignación (por diametralmente opuesta que mi postura se halle con respecto a la de aquel crítico argentino que proponía, si bien recuerdo, nada menos que la supresión de "Alturas de Macchu Picchu» del corpus del Canto General...).

Por eso creo que es tiempo - tal vez sea un poco tarde- de poner a mi tardía crítica unas comillas dictadas no por el arrepentimiento o lo "científicamente correcto" sino por la obra misma y la índole de su desarrollo.

«Atesoro las equivocaciones de mi canto», declara el poeta de la "Sonata crítica". Es preciso darle todo su peso al verbo: las equivocaciones no como un lastre sino como un tesoro de experiencias, y como el precioso testimonio del incesante recomponerse de una obra metida, más que cualquier otra, en «las mesmas aguas de la vida", para decirlo con las machadianas palabras de Santa Teresa.

«Atesoro las equivocaciones de mi canto»: lección dada por el poeta al crítico, poniendo a éste entre definitivas comillas, y aconsejándole el silencio.
Pablo Neruda: "Sobre una poesía sin pureza", op. cit.l, p. 1040.

\section{9}

Roberto Salama: Para una crítica a Pablo Neruda, Buenos Aires, Ed. Cartagena, 1957. 